\title{
POLYMERASE CHAIN REACTION (PCR) TECHNIQUES FOR THE IDENTIFICATION OF UNCULTIVABLE ORAL MICROORGANISMS
}

Himratul-Aznita W.H. Polymerase chain reaction (PCR) techniques for the identification of uncultivable oral microorganisms. Annal Dent Univ Malaya 2001; 8: 43-49.

\section{ABSTRACT}

Until today there are still a high percentage of oral microorganisms have not been identified due to inability to isolate using the cultural method. However, identification of uncultivable microorganisms associated with disease will permits clinicians for a more accurate diagnosis, treatment and preventive measures. Unculturable microorganisms are also involved in disease and may account for treatment failure since their susceptibility to antimicrobial agents would be unknown. Thus, the opportunity for a rational approach to the treatment of disease relies on the state of knowledge concerning its aetiology and pathogenesis. Recently developed molecular methods have made it possible to characterise mixed microflora in their entirety, including the substantial numbers of unculturable bacteria. The development of rapid molecular methods like PCR provides a reliable identification of unculturable microorganisms. This paper will review the current literature regarding the PCR techniques used to identify uncultivable oral microflora.

Key words: Identification, detection, PCR, uncultivable oral microorganisms.

\section{INTRODUCTION}

Specific anatomical structures in the oral cavity provide bacteria with diverse habitats characterized by different $\mathrm{pH}$, redox potential and nutrient availability. Additionally, mastication, salivary defence mechanisms and diet exert different influences on bacteria at sites and as a consequence, the ecosystems support the growth of dissimilar bacterial communities (1). For many decades, it has been an important part of research to enumerate and identify the oral microflora that has a broad range of genera. It is estimated that $50 \%$ of the oral flora is unculturable and the proportion of unculturable organisms at other body sites remains unknown (2). The complexicity of bacterial community and the fastidious nature of some of its population members have hampered the analysis of normal human flora and of polymicrobial infections in human. Independently of different study designs and detection methods, including bacterial culture methods, immunoassays and nucleic acid based techniques use different principles for bacterial identification and the results obtained by using different methods may vary.
Review Article

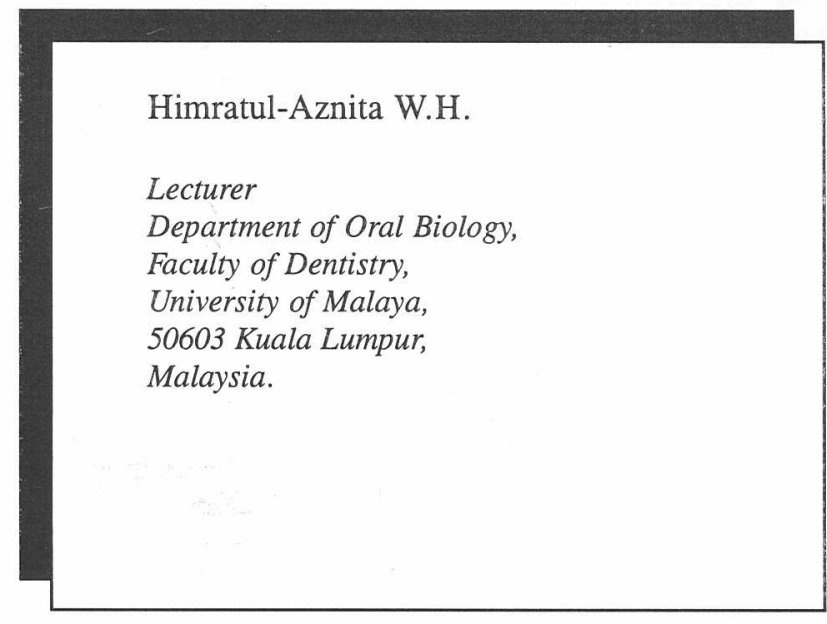

Culture method is frequently used as a reference method, which involves the combination of culture dependent and differentiation of isolates. Generally, samples are cultivated on a non-selective agar or enriched media, whereas selective culture employs antimicrobial agents to suppress non-target microorganisms and thereby improve the detection limit. Growth colonies were differentiated and identified after passing through a series of physiological and biochemical tests. Culture methods yield no information on uncultivable forms such as the bacteria and spirochetes (3) and require experienced personnel, relatively timeconsuming, expensive and also rely on the presence of viable microorganisms and are likely to show inherent technical limitations (4). Cultural methods have multiple sources of method error relating to the adequacy of the dispersal method, the number of dilutions involved, the plating method, the adequacy of the media, the gas atmosphere used for incubation, the length of incubation, and the reliability of the tests (3). Yet, because of historical precedent, it is generally accepted that the cultural procedure is a reliable reference for determining the presence or absence of a cultivable species, however this acceptance has changed with the development of highly specific immunological reagents and DNA probes (3).

In contrast, immunodiagnostic methods do not discriminate between viable and non-viable bacteria as in culture method. Most immunodiagnostic methods provide a quantitative or semi-quantitative estimate of the target microorganism (5). Immunodiagnostic tests are targeted to specific bacterial species. The immunoassays use antibodies to detect antigens on target bacteria. These methods are rapid, relatively inexpensive, and they can detect non-viable species. Disadvantages of these tests include possible cross reactivity between similar species and inability to determine antibiotic sensitivity or resistance. In addition, this method generally show poorer detection limits than nucleic acid probe or PCR assays. 


\section{MOLECULAR TECHNIQUES FOR IDENTIFYING MICROBIAL DIVERSITY}

Molecular biology approaches used for the identification and differentiation of bacterial species can be categorised into main groups such as (i) hybridization of nucleic acid (DNA/RNA) with DNA probes and genomic fingerprinting, (ii) sequencing of ribonucleic acid $(5 \mathrm{~S}, 16 \mathrm{~S}, 23 \mathrm{~S})$. (iii) $\mathrm{PCR}$ with species-specific primers and PCR fingerprint techniques which can detect DNA polymorphisms in the identification of bacterial species. The application of modern molecular biology enables the identification of microorganisms without the need of bacterial culturing is leading to the identification of an even more diverse oral microflora, in particular the unculturable species (6). These molecular techniques based on non-amplification nucleic acid probe procedures are more reliable primary reference standards than the cultural method. Importantly, it provides rapid, accurate and inexpensive microbial identification of pathogens and will probably play increasing importance in future diagnostics. Application of the DNA probe technique in clinical dentistry is useful for identification of the presence of bacterial DNA fragments within any type of sample based on crossreactivity patterns with known bacterial types. Also, it allows the examination of a large number of samples that are difficult to explore with conventional cultural techniques. Nucleic acid probe assays rely on the unique double stranded structure of the DNA molecule to detect the target microorganisms. Each species contains unique segments of DNA thus, allowing the possibility of constructing nucleic acid probes that will hybridize to these sequences. The detection of target microorganisms is, therefore, based on the binding of the nucleic acid probes to the complementary strands of nucleic acid in these unique regions. This technique requires preparing pieces of single-stranded DNA labelled with an enzyme or radioisotope that can locate and bind to their complementary nucleic acid sequences with low crossreactivity to non-target microorganisms. Probes can be of different types; (i) whole genomic, (ii) cloned or (iii) oligonucleotide probes and may target for whole genomic DNA or individual genes. Whole genomic probes are constructed from the entire genome of the target microorganism and are more likely to cross react with non-target organisms due to the presence of homologous sequences between different bacterial species. This type of probe has several advantages over other nucleic acid probes. It is the simplest to construct and the least expensive to produce. Cloned probes are isolated sequences of DNA that do not show cross-reactivity and are produced in quantity by cloning in a plasmid vector within a temporary host microorganism such as Escherichia coli. Oligonucleotide probes are usually 10 $50 \mathrm{bp}$ whereas the other probe types are often several kilo base pairs in length. The sequences of oligonucleotide probes are obtained from unique hyper variable regions of ribosomal RNA of the target microorganism. Oligonucleotide probes for oral species are relatively insensitive, detecting only $10^{6}$ cells, compared to cloned and whole genomic probes, which can routinely identify $10^{3}$ target cells (4). This probe based on species-specific sequences may display limited or no cross-reactivity with non-target organisms. Oligonucleotide probes complementary to variable regions of the $16 \mathrm{~S}$ rRNA genes have been used for the detection of various bacterial species (5). Thus, DNA probe technology provides both a sensitive and specific assay and alleviates the concern for transport of fastidious microorganisms. The procedure includes (i) disruption of bacterial cells with denaturation of DNA, (ii) immobilization of DNA onto a nitrocellulose filter, (iii) blocking unbound nitrocellulose with non-specific DNA, (iv) hybridization of the filter with labelled probe, (v) washing and detection of bound probe (4). Socransky et. al. (5) developed a checkerboard DNADNA hybridization assay for the detection of oral bacteria. In this method, the sample DNA is released and immobilized on a nitrocellulose membrane. The membrane-bound DNA is then allowed to hybridize with either digoxigenin-labelled whole genomic DNA or $16 \mathrm{~S}$ rRNA-based oligonucleotide probes. The checkerboard assay is able to simultaneously screen for the presence of up to 43 different bacterial species in 43 specimens using a single nitrocellulose membrane. The checkerboard method is particularly suitable for largescale microbiological studies of the sub gingival micro biota. This method overcomes many of the limitations of culture and is more rapid, cost-effective than antibody-based techniques and able to identify uncultivable or difficult to grow species. However the disadvantages of this method include the fact that detection is limited to species for which probes are available, the need for precise quality control and the possibility of cross reactions (7).

\section{POLYMERASE CHAIN REACTION (PCR) AND RELATED TECHNIQUES}

PCR amplification of DNA has enabled the amplification of specific genes and allowed the rapid characterisation of both entire genome as well as specific genes in large numbers of organisms (2) including oral spirochetes that cannot be grown in artificial culture (6). Genes encoding ribosomal RNA have been found to be particularly useful for the construction of phylogenetic trees reflecting the evolution of bacteria. Due to the need to preserve function, these genes have been conserved throughout evolution (2). This technique amplify the number of copies of a specific region of DNA, in order to produce enough DNA to be adequately tested, which can be used to identify with a very high-probability, disease-causing viruses and/or bacteria, a deceased person, or a criminal suspect. The DNA of different microorganisms is different because there will always be genes whose DNA sequences differ among different organisms. Therefore, by identifying the genes which are different, one can use this information to identify an organism.

PCR is based on three simple steps required for any DNA synthesis reaction; 
(i) denaturation of the template into single strands,

(ii) annealing of primers to each original strand for new strand synthesis, and

(iii) extension of new DNA strands from primers.

The advantages of using PCR over any other techniques are;

(i) DNA can be amplified rapidly and accurately which allow the identification of bacterial species or strain (8).

(ii) Do not require viable microorganisms for enumeration of bacteria from specimens.

(iii) Allows off-site collection of specimens, due to nonrequirement for live bacteria in the enumeration of specific species and need less cumbersome transport materials.

(iv) PCR is reproducible and extremely sensitive requiring only small numbers of organisms for analysis. This sensitivity has been exploited as the basis for a number of tests, including the detection of pathogens $(9,10,11)$.

Ribosomal RNAs (rRNAs) are ancient molecules, functionally constant, universally distributed, and well conserved across broad phylogenetic distances. In procaryotes, there are three different sizes of ribosomal RNA molecules, 5S, 16S and 23S (12). 5S rRNA has been used for phylogenetic measurements, but its small size ( 120 nucleotides), limits the information obtainable from this molecule. Because 16S rRNA is more experimentally manageable than $23 \mathrm{~S}$ rRNA, it has been used extensively for bacterial identification and to develop the phylogeny of procaryotes (12). The $16 \mathrm{~S}$ rRNA gene has been found to be particularly useful because its size of approximately 1500 bases in length is an ideal size for molecular evolution studies. It is both long enough to provide useful discriminatory information and also short enough for easy sequencing $(2,13)$. Thus, $16 \mathrm{~S}$ rRNA gene is the most widely used gene to date and have been amplified from a variety of sources, including the environment and human infections, and sequenced to reveal the diversity of organisms present at the site (2).

The conserved regions are extremely useful for the design of PCR primers, while the variable regions contain the information useful for strain discrimination. Woese (14) in his environmental studies used 16S rRNA as a tool for dissecting complex bacterial communities and which gave rise to the subspecialty of molecular microbial ecology. This molecular approach has been applied successfully to analyze environmental samples, such as photosynthetic microbial mats (15), oligotrophic sea water (16), soil (17) and uncultivable infectious agents associated with disease from human, have also been identified in bacillary angiomatosis (18) and Whipple's disease-associated bacterium Tropheryma whippelii (19). The primary amplification step is crucial since the specificity of the primers used will determine the organisms whose 16S rRNA genes are amplified.
Later, Lane (20) described a selection of primers of varying specificities which proved extremely useful and have been widely adopted. However, DNA samples extracted from various sources, including deep sea sediment and oral bacteria were found to be poor templates for amplification on the 16S rRNA gene with amplimers such as $27 \mathrm{f}$ and either $1492 \mathrm{r}$ or $1392 \mathrm{r}$ (numbering is based on the Escherichia coli 16S rRNA gene (21).

Marchesi et. al. (22) designed and evaluated PCR primers $63 \mathrm{f}$ and $1387 \mathrm{r}$ for amplification of $16 \mathrm{~S}$ rRNA genes from bacteria. They were found to be more useful for 16S rRNA gene amplification compared to the currently used primers $27 \mathrm{f}$ and $1392 \mathrm{r}$. This study had attempted to optimise the PCR conditions for $27 \mathrm{f}-1392 \mathrm{r}$ by altering the annealing temperature, $\mathrm{Mg}^{2+}$ concentration and DNA template concentration. Also by including the PCR additives bovine serum albumin, triton-X-100, T4 gene 32 protein, polyethylene glycol 8000 and glycerol, finally, they were successful when the newly redesign amplimers $63 \mathrm{f}$ and $1387 \mathrm{r}$ were used successfully with the difficult DNA samples. The wide adoption of amplimers 27f, 1392r and 1492r is empirically based, and their utility for investigating molecular ecology of natural bacterial communities is often assumed, and has not been systematically tested (22). Although $63 \mathrm{f}$ and $1387 \mathrm{r}$ showed some theoretical bias in the experiment done by Marchesi et. al. (22). In practical they were more successful than amplimer pair 27f-1392r and able to amplify 16S rRNA genes from a wider range of bacteria than other primers which are commonly used for bacterial community analysis. So far, other primers have not been tested in the systematic way described for $63 \mathrm{f}-1387 \mathrm{r}$ by Marchesi et. al. (22). However, the aim of which is to minimise PCR bias, and underline the point that the theoretical design of PCR amplimers is only the beginning and that systematic empirical testing of the amplimers is of paramount importance.

\section{PERIODONTITIS}

Given the enormous complexity of the oral flora, an alternative approach would be focus in on particular groups of organisms suspected to be important in oral disease. Spirochetes have been long associated with periodontitis (23) but because the majority of species cannot be cultured, the important of these organisms in disease in unknown. Choi et. al. (24) successfully screened a 16S rRNA gene library generated from a periodontal pocket with universal PCR primers using a Treponema-specific oligonucleotide probe. Riviera et. al. (25) described that some spirochetes have been particularly associated with active disease and thus been named the pathogen-related oral spirochetes (PROS), while Wade (13) discovered that $91 \%$ of PROS are unculturable. Therefore, there is great hope that the approach will assist in elucidating the role of treponemes in the pathogenesis of periodontal infections by associating defined species with healthy or diseased sites (24). 
Another important group of organisms in oral infections are the oral asaccharolytic Eubacterium species which present in large number in periodontitis $(2,26)$, but are rarely found in gingival health. However they are difficult organisms to cultivate, being highly sensitive to oxygen and also difficult to identify because of their general unreactivity in biochemical tests. Studies by Spratt et. al. (27) and Harper-Owen et. al. (28) showed that the indifferent growth of culturable members of the group suggests the presence of a substantial unculturable population. This study was to design and validate specific PCR primers for these phylotypes and to determine their incidences in samples collected from healthy and diseased periodontal tissues. The need for extensive validation of novel primers was demonstrated by the considerable cross-reactivity with related species that was seen with some of the primers (28). Two specific reverse primers were devised for each phylotype, and these were used in duplex PCRs with universal forward and reverse primers. Thus multiple primers used, were to maintain high specificity of the detection system for uncultivable microorganism

\section{DENTOALVEOLAR ABSCESS}

Dentoalveolar abscesses are acute infections associated with the teeth, arising from pulpal infection secondary to dental caries. Cultural analysis has revealed they are associated with a restricted group of organisms from the genera Fusobacterium, Peptostreptococcus, Prevotella and Streptococcus.
Dymock et. al. (29) successfully screened for unculturable bacteria associated with this disease by PCR technique of $16 \mathrm{~S}$ rRNA amplification. Samples of pus were obtained from acute abscesses by a needle and syringe. DNA was extracted from the whole sample and the 16S rRNA genes amplified. These were singularised by cloning, re-amplified and digested with restriction endonucleases to give a RFLP profile. These profiles were then compared with similar profiles obtained from isolates cultured from the sample. In this way cloned genes isolated from organisms not represented in the culturable portion were identified (24). A general overview of the method is outlined in Figure 1. Five predominant uncultured organisms were identified as Porphyromonas gingivalis, Prevotella oris, Peptostreptococcus micros-related, Zooglea ramigerarelated and the other was distantly related to the genus Prevotella (29).

Using the same approach, Wade et. al. (2) have identified uncultivable novel anaerobic species in dentoalveolar abscesses with universal primers $27 \mathrm{f}$ and $1492 \mathrm{r}$ for amplification of $16 \mathrm{~S}$ rRNA genes.

\section{ENDODONTIC INFECTIONS}

There is now considerable evidence that endodontic diseases (pulpal and periradicular inflammation) are directly associated with bacterial invasion of the dentine, root canal system, and periradicular tissue. The primary target of these infections is the connective tissues of the pulp, which is completely enclosed within rigid dentine.



Figure 1. Flow chart showing the strategy for detection of uncultivable bacteria in dentoalveolar abscess

(Dymock et al. 1996). 
Dentine structure, permit selected anaerobic bacteria to invade the dentine, the root canal system, and sometimes the periradicular tissue (30). Williams et. al. (30) have identified uncultivable microbial communities in dentine and cementum. They adapted the same PCR technique as Choi et. al. (24), amplifying the 16S ribosomal RNA. Tooth with carious lesions, carious tooth, carious tooth associated with pain, heavily restored tooth and intact tooth produced amplifiable product from PCR analysis. Homologies of $95 \%-99 \%$ with several gram positive taxa that have not been previously described in the oral cavity were apparent in this study. Furthermore, the homologies of several sequences with any DNA sequences of Eubacterium were low; suggesting that there are bacteria in the dentine and cementum that have not yet been classified and are probably unique to the oral cavity mainly because of the limited nutrients available and the restricting environment of the dentinal tubules (30).

\section{LIMITATIONS}

Unfortunately, this straightforward and universal approach is hampered by a number of problems, which may lead to erroneous results. One of the drawbacks of the molecular technique for this application is that it may detect dead bacteria which have been killed by the host immune system but whose DNA remains present in the sample or even fairly short fragments of remaining DNA (31).

Another problem arise with this technique is with the several commonly used amplimers which have been constructed theoretically, using incomplete database of $16 \mathrm{~S}$ rRNA sequences from cultured organisms and have not been tested systematically (22). However, the aim of which is to minimise PCR bias, and underline the point that the theoretical design of PCR amplimers is only the beginning and that systematic empirical testing of the amplimers is of paramount importance. There are also primers which consistently failed to work with difficult samples such as PCR primers described by Lane (20), although these primers can work efficiently with other culturable organisms $(32,33)$. This may explain the detection of normally culturable organisms by the molecular method alone. Despite its limitations, comparative rRNA analysis does represent the currently best approach for the identification and phylogenetic classification of unculturable microorganisms and the description of the population structure of complex microbial communities.

\section{CLINICAL ORAL MICROBIOLOGY}

There is an important behavioural/educational aspect which relates to the need for an objective biological test to diagnose oral diseases. A better understanding of the bacterial species involved in each disease category would improve the clinicians ability to permit more accurate diagnosis and provide rational therapeutic endpoints for testing treatment modalities, such as the need and type of antibiotics prescribed, adjusting maintenance schedules. Also, the informations obtained will help the clinicians to evaluate current and predict future disease status in order to determine preventive measures and the endpoint of treatment (5). Thus, the microbiological specificity paradigm has already changed the way that the research community and some clinician view oral diseases. The goal of therapy is to target and then reduce and/or the eliminate the specific pathogens. The opportunity for a rational approach to the treatment of disease depends in large measure on the state of knowledge concerning its aetiology and pathogenesis. Although most of the commonest oral diseases such as dental caries, periodontitis etc are rarely life-threatening, the direct cost of treating these common oral diseases is enormous and they are the most expensive infections that the majority of individual will have to contend with in their lifetime (34). The bacteria associated with dentoalveolar abscesses are principally viridan group streptococci, particularly the Streptococcus milleri group, Fusobacterium sp., Prevotella sp., Porphyromonas sp. and Peptostreptococcus sp. However, it is estimated that approximately $50 \%$ of the oral flora is unculturable (29). Today, we are aware that unculturable microorganisms have been isolated and identified from common oral diseases such as periodontitis, dentoalveolar abscesses and endodontic infections. However, it is not impossible that other oral infection harbours unculturable microorganisms as well. Currently, there has been increasing reports and concern among clinicians despite the widespread use of antibiotics in Ludwig's angina disease, one of the oral infections that resulted with a very high mortality rate among patients. Although with the introduction of antibiotic therapy, mortality rate has decreased to less than $10 \%$ from $50 \%(35,36)$ scientists and dental clinicians must have a thorough study/research relating to microorganisms involved, in order to overcome this deadly disease. Ngeow (37) reported that Streptococcus species have been isolated from a 3 years old child with Ludwig's angina. This indicates that further study is needed as there are possibilities of other microorganisms involved including unculturable microorganisms. It is likely therefore, that at least some members of the unculturable part of the flora are involved in disease and indeed, may account for treatment failure since their susceptibility to antimicrobial agents would be unknown.

\section{CONCLUSIONS AND FUTURE DEVELOPMENT}

The failure to grow an organism on artificial culture media obviously means that the correct environment for growth has not been provided. If an organism cannot be cultured then obviously its biological properties cannot be determined. Therefore, methods for the study of unculturable bacteria have long been sought. The key to the development of techniques for the investigation of unculturable organisms came from the realisation that the sequence information contained in biological macromolecules could be deciphered and would include 
regions specific to the whole organism itself. Thus, molecular methods are now available which allow the characterisation of the unculturable portion of bacterial communities. There are a number of possible reasons for this. Artificial culture media may lack the nutrients required by the organism or incubation atmosphere or temperature may be sub-optimal. Alternatively, media may contain substances toxic for growth or other bacteria in the sample may produce inhibitory substances. Currently, the lower limit of sensitivity of DNA probes which are commercially available is approximately 6000 bacteria and may not provide the sensitivity necessary for detection of pathogens in those specific sites such as dentine, cementum or periodontal pocket in which the number of pathogens are low or fluctuates (38). The development of rapid molecular methods like PCR not only it is more sensitive for bacterial identification (i.e. 100 cells), it also enable the investigation of mixed microflora associated with disease in their entirety without the inherent biases of culture. The procedures are obviously applicable to infections at all body sites and should lead to a more complete understanding of associations between bacteria and disease. Although PCR method is relatively time consuming at present, it is still considered as one of the most rapid detection method for unculturable bacteria. With these PCR approaches, a number of novel sequences, which do not correspond to known, culturable organisms, have been identified. The ability to identify both the culturable and unculturable microorganisms associated with disease will improve our knowledge of the aetiology of oral pathogen related diseases and allow the discovery of additional marker organisms of value in disease diagnosis and treatment monitoring. These can be used to determine the prevalence of the organisms in healthy and diseased tissues and, if specific associations are found, might be useful markers of disease activity. In conclusion, molecular techniques such as those described in this review are a new, culture independent era of medical microbiology and there is great hope that the approach will assist in elucidating the role of microorganisms in the pathogenesis of oral infections. Clearly, further work is required to characterize the microbial populations associated with oral health and disease. Thus, molecular methods provide the tools for the detection of unculturable microorganisms and hopefully will allow a far better understanding of oral diseases.

\section{REFERENCES}

1. Asikainen S, Chen C. Oral ecology and person-toperson transmission of Actinobacillus actinomycetemcomitans and Porphyromonas gingivalis. Periodontology 2000. 1999; 20: 65-81.

2. Wade WG, Spratt DA, Dymock D, Weightman AJ. Molecular detection of novel anaerobic species in dentoalveolar abscesses. Clin. Infect. Dis. 1997; 25 (Suppl. 2): S235-S236.
3. Loesche WJ. DNA probe and enzyme analysis in periodontal diagnostics. J. Periodontology. 1992; 63: 1102-9.

4. Savitt ED, Keville MW, Peras WJ. DNA probes in the diagnosis of periodontal microorganisms. Arch. Oral Biol. 1990; 35 (Suppl.): 153S-159S.

5. Chen K, Neimark H, Rumore P, Steinman CR. Broad range DNA probes for detecting and amplifying eubacterial nucleic acids. FEMS Microbiol. Lett. 1989; 57: 19-24.

6. Slots J. Actinobacillus actinomycetemcomitans and Porphyromonas gingivalis in periodontal disease : Introduction. Periodontology 2000. 20; 7-13.

7. Haffajee AD, Socransky SS, Feres M, XimenezFyvie LA. Plaque microbiology in health and disease. In:Newman HN, Wilson M, editor. Dental plaque revisited-oral biofilms in oral health and disease. Proceedings of a conference held at the Royal College of Physicians, London, 3-5th Nov.1999; 255-282.

8. Olive DM, Bean P. Principles and applications of methods for DNA-based typing of microbial organisms. J. Clin. Microbiol. 1999; 37: 1661-1669.

9. Berriddge BR, Fuller JD, de Azavedo J, Low DE, Bercovier H, Frelier PF. Development of specific nested oligonucleotide PCR primers for the Streptococcus iniae 16S-23S ribosomal DNA intergenic spacer. J. Clin. Microbiol. 1998; 36: 2778-2781.

10. Greisen K, Loeffelholz M, Purohit A, Leong D. PCR primers and probes for the 16S rRNA gene of most species of pathogenic bacteria including bacteria found in cerebrospinal fluid. J. Clin. Microbiol. 1994; 32: 335-351.

11. Jaton K, Sahli R, Bille. Development of polymerase chain reaction assays for detection of Listeria monocytogenes in clinical cerebrospinal fluid samples. J. Clin. Microbiol. 1992; 30: 1931-1936.

12. Brock TD, Madigan TM. Biology of microorganisms, $6^{\text {th }}$ ed. Prentice Hall, Englewood Cliff, New Jersey. 1991; 677-702.

13. Wade W. Unculturable bacteria in oral biofilms. In:Newman HN and Wilson M, editor. Dental plaque revisited-oral biofilms in oral health and disease. Proceedings of a conference held at the Royal College of Physician, London, 3-5th Nov.1999; 313-322.

14. Woese CR. Bacterial evolution. Microbiol. Rev. 1987; 51: 221-271. 
15. Ward DM, Weller R, Bateson MM. 16S rRNA sequences reveals numerous uncultured microorganisms in a natural community. Nature (London). 1990; 345: 63-65.

16. Giovannoni SJ, Britschgi TB, Moyer CL, Field KG. Genetic diversity in Sargasso Sea bacterioplankton. Nature (London). 1990; 345: 60-63.

17. Liesack W, Stackebrandt E. Occurrence of novel groups of the domain Bacteria as revealed by analysis of genetic material isolated from an Australian terrestrial environment. J. Bacteriol. 1992; 174: 5072-5078.

18. Relman DA, Schmidt TM, MacDermott RP, Falkow $S$. Identification of the uncultured bacillus of Whipple's disease. N. Engl. J. Med. 1992; 327: 293-301.

19. Wilson KH, Blitchington R, Frothingham R, Wilson JAP. Phylogeny of the Whipple's-disease-associated bacterium. Lancet. 1991; 338: 474-475.

20. Lane DJ. 16S/23S rRNA sequencing. In Stackebrandt E and Goodfellow M, editor. Nucleic acid techniques in bacterial systematics. John Wiley and Sons Ltd., Chichester, United Kingdom. 1991; 115-175.

21. Brosius J, Palmer JL, Kennedy HP, Noller HF. Complete nucleotide sequence of a $16 \mathrm{~S}$ ribosomal RNA gene from Escherichia coli. Proc. Natl. Acad. Sci. USA. 1978; 75: 4801-4805.

22. Marchesi JR, Sato T, Weightman AJ, Martin TA, Fry JC, Hiom SJ, Wade WG. Design and evaluation of useful bacterium-specific PCR primers that amplify genes coding for bacterial 16S rRNA. Appl. Env. Microbiol. 1998; 64: 795-799.

23. Listgarten MA, Hellden L. Relative distribution of bacteria at clinically healthy and periodontology diseased sites in humans. J Clin Periodontol. 1978; 5: 115-132.

24. Choi BK, Paster BJ, Dewhirst FE, Gobel UB. Diversity of cultivable and uncultivable oral spirochetes from a patient with severe destructive periodontitis. Infect. Immun. 1994; 62: 1889-1895.

25. Riviera GR, Wagoner MA, Baker-Zander SA., Weisz KS, Adam DF, Simonson L, Lukehart SA. Identification of spirochetes related to Treponema pallidum in necrotising ulcerative gingivitis and chronic periodontitis. New Engl. J. Med. 1991; 325: 539-543.

26. Moore WEC, Holdeman LV, Cato EP, Smibert RM, Burmeister JA, Ranney RR. Bacteriology moderate (chronic) periodontitis mature adult humans. Infect Immun. 1983; 42: 510-515.
27. Spratt DA, Weightman AJ, Wade WG. Diversity of oral asaccharolytic Eubacterium species in periodontitis-identification of novel phylotypes representing uncultivated taxa.1999; 14: 56-59.

28. Harper-Owen R, Dymock D, Booth V, Weightman AJ, Wade WG. Detection of unculturable bacteria in periodontal health and disease by PCR. J. Clin. Microbiol. 1999; 37: 1469-1473.

29. Dymock D, Weightman AJ, Scully C, Wade WG. Molecular analysis of microflora associated with dentoalveolar abscesses. J. Clin. Microbiol. 1996; 34: 537-542.

30. Williams JC, Gharbia SE, Gulabivala K, Rajendram D, Mehta N, Huittson R, Collins MD, Shah HN. Noncultivable microbial communities in dentine and cementum : A molecular analytical approach. Clin. Infect. Dis. 1997; 25 (Suppl. 2): S233-S234.

31. Wahlfors J, Meurman JH, Vaisanen P, Alakuijala, Korhonen A, Torkko H, Janne J. Simultaneous detection of Actinobacillus actinomycetemcomitans and Porphyromonas gingivalis by a rapid PCR method. J. Dent. Res. 1995; 74: 1796-1801.

32. De Long EF. Archaea in coastal marine environments. Proc. Natl. Acad. Sci. USA. 1992; 89: $5685-5689$.

33. Reysenbach AL, Wickham GS, Pace NR. Phylogenetic analysis of the hyperthermophilic pink filament community in Octopus Spring Yellowstone National Park. Appl. Environ. Microbiol. 1994; 60: 2113-2119.

34. Oguntebi B, Slee AM, Tanzer JM, Langeland K. Predominant microflora associated with human dental periapical abscesses. J. Clin. Microbiol. 1982; 15: 964-969.

35. William AC, Guralnick WC. The diagnosis and treatment of Ludwig's angina. N. Engl. J. Med. 1943; 228: 445-450.

36. Hought RT, Fitzgerald BE, Latta JE, Zallen RD. Ludwig's angina : report of two cases and review of the literature from 1945 to January 1979. J. Oral Surg. 1980; 38: 849-855.

37. Ngeow WC. Ludwig's angina infection in a child : a cause for concern. Annal. Dent. Univ. Malaya. 1999; 6: 31-32.

38. Watanabe K, Frommel TO. Detection of Porphyromonas gingivalis in oral plaque samples by use of the polymerase chain reaction. J. Dent. Res. 1993; 72: 1040-1044. 